\title{
La construcción política de la hechicera: discursos de género y poder en "El caso de Juana de Mansilla" de Bernal Díaz del Castillo
}

\section{The Political Construction of the Sorceress: Discourses of Gender and Power in “The Case of Juana de Mansilla” by Bernal Díaz del Castillo}

Silvia Ruiz Tresgallo [silvia.ruiz@uaq.mx]

Universidad Autónoma de Querétaro, México

\section{RESUMEN}

En los capítulos CLXXXV-CLXXXVIII (185 y 188) de Historia verdadera de la conquista de la Nueva España (1632) Bernal Díaz del Castillo describe a la misma mujer -Juana de Mansilla-como hechicera y como matrona romana. Debido al retrato ambiguo que se nos ofrece de esta dama, este ensayo explora los mecanismos a través de los cuales el poder político construye y deconstruye a la bruja. Consideramos que el ejemplo de la esposa de Alonso Valiente resulta especialmente pertinente para nuestro estudio porque desvela el uso político del cuerpo femenino según la agenda de aquellas masculinidades que poseen la hegemonía.

\section{Palabras Clave}

hechicería; política; género; conquest

\section{Abstract}

Chapters CLXXXV-CLXXXVIII (185 y 188) in Bernal Díaz del Castillo's Historia verdadera de la conquista de la Nueva España (1632) describe the same woman -Juana de Mansilla - as both, a sorceress and a Roman matron. This essay explores the political mechanisms through which patriarchal power constructs and deconstructs the witch. The example provided by Alonso Valiente's wife is especially relevant to our study because it reveals the political use of the female body according to the agenda of those masculinities who rule.

\section{KEYWORDS}

sorcery; politics; gender; conquest 
Dentro del marco de este manuscrito, se ha registrado en la Universidad Autónoma de Querétaro (México) un proyecto de investigación titulado "Acercamientos trasatlánticos a la construcción demoniaca de América: Hechicería, picaresca y política en la literatura colonial" en el que se examinan narrativas históricas y literarias junto con archivos de la inquisición de la época colonial. El presente ensayo forma parte de este proyecto que se acerca a la imagen de la bruja como una construcción social y política manipulada desde el poder. Dentro de las tareas de investigación y edición de este ensayo han participado las estudiantes Juliana Romero Rodríguez, de la licenciatura en estudios literarios, y Andrea Margarita Mancillas Rodríguez, perteneciente a la licenciatura en lenguas modernas español de la misma universidad.

\section{Introducción}

En los capítulos CLXXXV-CLXXXVIII (185 y 188) de Historia verdadera de la conquista de la Nueva España (1632), escrita en el siglo XVI, Bernal Díaz del Castillo describe a la misma mujer -Juana de Mansilla - como hechicera y como matrona romana. Sorprende comprobar que el retrato ambiguo de la dama transcurre en la narrativa del castellano del discurso nigromántico al maternal, dependiendo de la interpretación del grupo masculino que ostente la jefatura. Por esta razón, a lo largo de este ensayo exploramos los mecanismos a través de los cuales el poder político construye a la bruja. En un clima social de persecución, en que los enemigos del autonombrado gobernador son represaliados, observamos la "ansiedad masculina" (Weissberger 2002) que provoca una mujer que se resiste al poder. La acusación de brujería adjudicada a la protagonista tiene lugar en una coyuntura de tensión política en la que aquellos que cuestionan la legitimidad gubernamental del factor son castigados bajo distintas y variadas imputaciones en una auténtica "caza de brujas". Las cuestiones de género y poder también adquieren una posición central en nuestro estudio puesto que nos preguntamos cómo se enfrenta el patriarcado ante una mujer que se rebela ante sus leyes y si se puede extraer un beneficio de esta aparente ingobernabilidad.

Proponemos que Díaz del Castillo construye a Juana de Mansilla como un tropo que el patriarcado demoniza o ensalza de acuerdo a sus intereses políticos. En primer lugar, nos acercamos al personaje histórico de Juana de Mansilla dentro del contexto político en que se desarrolla esta narrativa para demostrar su representación a través de una perspectiva masculina que conviene al narrador de la historia. En esta línea de pensamiento, demostraremos la inversión de los papeles adjudicados a cada género, puesto que la protagonista toma el rol de los hombres, al enfrentarse al factor y no retractarse de sus afirmaciones a pesar del castigo. Consideramos que el correctivo proporcionado por el factor Salazar al cuerpo de la joven supone un tipo de humillación pública que pretende en realidad la deshonra de Cortés y sus hombres; las figuras masculinas a las que la dama está afiliada. A primera vista podría parecer que Juana es una mujer autónoma y/o disidente, pero, como demostraremos en este ensayo, Díaz del Castillo simplemente la dibuja como una extensión del cuerpo y la voz de su esposo al que pertenece por un lazo matrimonial.

Por último, estudiaremos el método de incorporación de la "hechicera" Juana al discurso patriarcal de los vencedores, para exponer su inclusión dentro del nuevo y restaurado orden con un alegato familiar adaptado a los valores políticos y religiosos del Imperio. "Doña” Juana pasa a formar parte de un grupo selecto de mujeres “excepcionales”, utilizadas políticamente por el 
patriarcado, que en un momento histórico fueron demonizadas pero después fueron incorporadas al discurso de la nación o del Imperio con el papel de santas, madres o vírgenes. Consideramos que el ejemplo de la esposa de Alonso Valiente resulta especialmente pertinente para nuestro estudio porque desvela el uso patriarcal del cuerpo femenino según la agenda de quien posee la hegemonía (Connell y Messerschmidt 2005). Es decir, aunque el performance realizado por la protagonista no varía, sí cambia el discurso político que interpreta estos hechos, el cual depende de la dialéctica de aquellas masculinidades que ostentan la jefatura. Para llevar a cabo este análisis utilizaremos los conceptos de masculinidades hegemónicas y feminidades enfatizadas de Connell y Messerschmidt (2005), las teorías sobre el castigo como espectáculo de Michel Foucault (2002 [1971]), y las disquisiciones de Silvia Federici (2010 [2004]) sobre la construcción patriarcal de la hechicera.

\section{Resumen}

Díaz del Castillo (1632) recoge, en lo que podría considerarse un relato corto dentro de su crónica, el caso de Juana de Mansilla, una mujer acusada de hechicería por Salazar en la Nueva España virreinal. El factor de México afirma que todos los hombres de Cortés han fallecido en Xicalango, con lo cual sus esposas deben casarse de nuevo. Juana se niega, al afirmar que su esposo está vivo, lo que causa que sea azotada públicamente por hechicera. El factor, junto con otros aliados, arrebata de forma ilegal el poder y encarcela, expulsa o condena a todo aquel que se rebela ante su posición. Sin embargo, como afirma Juana, los hombres de Cortés no están muertos, motivo por el que recobran de nuevo el control de la ciudad y encarcelan al factor. Para superar esta capitulación masculina ejemplificada en el cuerpo de Juana, el primer acto de restauración de Cortés en el poder será un desfile a caballo por la Ciudad de México en el que la joven recibe el título de "Doña" y una alabanza como matrona romana; una medida política que, como por arte de magia, transforma un cuerpo humillado en un cuerpo honrado y a una hechicera en una mujer valorada en el nuevo orden.

\section{Acercamiento histórico: género y política}

Juana de Mansilla, la protagonista de este estudio, fue la primera esposa de Alonso Valiente (Medina de las Torres 1482 - Nueva España 1564), uno de los primeros conquistadores del Nuevo Mundo. Sabemos que arribó a México desde España acompañando a su esposo, el cual gozaba de una posición de privilegio entre las tropas ya que era primo y secretario de Hernán Cortés. Prueba del status superior de Valiente, son los importantes puestos de jefatura que ocupó, ya que se desempeñó como uno de los primeros alguaciles mayores de la Ciudad de México y llegó a ser el primer encomendero de Tecamachalco. Además fue fundador de la ciudad de Puebla de los Ángeles ${ }^{1}$, localidad en la que ejerció el cargo de alcalde. Por tanto, la muchacha

1 Alonso Valiente llegó por primera vez al Nuevo Mundo acompañando a Cristóbal Colón en su última expedición. También fue uno de los conquistadores de Higüey en República Dominicana y de Borinquen (que Cristóbal Colón bautizó San Juan Bautista) en lo que hoy conocemos como Puerto Rico. Llegó junto con sesenta españoles a la Ciudad 
está ligada por matrimonio a una masculinidad hegemónica ya que su esposo forma parte de los viejos conquistadores de la Nueva España. Quizás por esta relación matrimonial el historiador Cruz (2009), en su libro sobre personajes ilustres de Puebla durante el siglo XVI, califica a Juana de Mansilla como "la gran dama del primer siglo" (113).

Conocemos a esta mujer a través de la Historia de la Conquista de México (1552) de Francisco López de Gómara y del texto de Bernal Díaz del Castillo que nos ocupa en este ensayo. Ambos historiadores incluyen los sucesos acaecidos a la dama dentro de los desmanes ocurridos durante el mandato del factor Salazar con una diferencia importante. Mientras que en el texto de Díaz del Castillo, Juana es disciplinada por la práctica de la hechicería, en la narración de López de Gómara esta acusación demoniaca recae sobre el factor. Gómara expresa: "Contole la muerte de Rodrigo de Paz, la prisión de Francisco de las Casas, los azotes de Juana de Mansilla, el saco de su casa, la nigromancia del factor Salazar, la ida de Juan de la Peña a España con dineros para el rey y cartas para Cobos" (1552: 354). Sorprende comprobar cómo la práctica de las artes ocultas funciona como una acusación política, ejercida desde el patriarcado, para justificar la aplicación de la violencia sobre el otro.

Díaz del Castillo enmarca la historia de Juana dentro de un periodo de crisis causado por los enfrentamientos entre distintos tipos de masculinidades. Las palabras del propio Hernán Cortés, que se dirige el 27 de junio de 1526 al ayuntamiento de México, hablan de las "artes e mañas" que emplean Gonzalo de Salazar y Pedro Almíndez de Chirinos para apoderarse de las tierras "tiranamente haciendo como han hecho muchos robos e muchas injusticias así a los españoles vecinos e moradores de estas tierras como a los naturales de ella” (Cruz 2009: 116). Según narra Díaz del Castillo en su Historia verdadera, Hernán Cortés en Guazagualco cede los poderes y provisiones al factor Gonzalo de Salazar y al veedor Pedro Almíndez Chirinos para asumir el control de la ciudad de México en el caso de que el tesorero Alonso de Estrada y el contador Rodrigo de Albornoz no gobernaran “bien” (1632: 490). Los estudios de Donoso Anes, que relatan las obligaciones de los cargos responsables de la buena administración de la Corona, definen al factor como el gerente Real de negocios. Se encargaba de todo lo relacionado con los ingresos en especie de la Real Hacienda, tenía a su cargo los almacenes donde se depositaban las mercancías del Rey, además de custodiar los depósitos de armas y munición. Por su parte, el veedor era el Oficial Real que recaudaba lo correspondiente al monarca (2008: 59-60). El gesto de Cortés, que buscaba garantizar la estabilidad del poder político, sólo sirve para alimentar las ambiciones del factor Salazar puesto que: “así como llegaron a México el factor y veedor con sus poderes fueron a hacerse muy amigos del mismo licenciado Guazo, que era alcalde mayor, y de Rodríguez de Paz, que era alguacil mayor, y de Andrés Tapia y Jorge de Alvarado y de todos los más conquistadores de México" (Díaz del Castillo 1632: 490).

Ante la ausencia de Cortés y sus hombres del centro político de poder, la Ciudad de México, otras masculinidades aprovechan para arrebatarle la hegemonía. Las alianzas de Salazar tienen como objetivo asumir el gobierno de la ciudad puesto que "y desde que se vio el factor con tantos amigos de su banda, dijo que el factor y el veedor habían de gobernar y no el tesorero ni el

de México tan sólo cuatro meses después de la toma de la ciudad. Valiente participó en la conquista de Michoacán y Pánuco. En 1524 fue también parte de la expedición de Cortés a Hibueras (Honduras). Esto es evidente en el nombramiento de Bernal Díaz del Castillo como capitán, documento firmado por Alonso Valiente. Allí, Valiente contribuyó a la conquista de las tres islas de Guanaja, en la costa norte de Honduras. 
contador" (Díaz del Castillo 1632: 491). Esta toma injusta del territorio, provocada por las ansías de poder económico y ascenso social, causan el caos político y el enfrentamiento violento de ambos bandos. Como afirma Díaz del Castillo; "sobre ello hubo muchos ruidos y muertes de hombres, los unos por favorecer al factor y al veedor, y otros por ser amigos del tesorero y contador." Es aquí donde se desata un ambiente de persecución propio de una caza de brujas política puesto que el factor y el veedor se quedan con el cargo de gobernadores y meten en la prisión al tesorero y al contador, además de a todos sus partidarios (Díaz del Castillo 1632: 491). Salazar y Chirinos abusan de la confianza de Cortés y dan un golpe de estado que, en opinión de quien escribe, tendrá nefastas consecuencias para la entidad territorial que conformará el virreinato.

Díaz del Castillo, como narrador de la historia, nos ofrece una visión de los hechos similar a la que después mantendrá Juana de Mansilla, puesto que desaprueba la conducta del factor al presentarlo como un mal gobernante. Desde que Salazar asume el poder prima un ambiente de caos y violencia ya que "cada día había cuchilladas y revueltas" (Díaz del Castillo 1632: 491). La razón reside en las malas decisiones del factor puesto que para garantizar su posición beneficia y regala a sus partidarios aunque no tengan méritos. Así, Díaz del Castillo presenta cómo el caos de la ciudad se extiende a las provincias: los indígenas se levantan en las comarcas de Zapotecas y Minxes y para combatirlos en el peñol de Coatlán, envía al veedor Chirinos con el cargo de Capitán. Sin embargo este último se muestra ineficaz en su labor, ya que "se salían los indios del peñol y le mataron ciertos soldados y le hirieron muchos otros" (Díaz del Castillo 1632: 491). Tras este fracaso, según la perspectiva de Díaz del Castillo, el factor se vuelve a equivocar ya que envía a otro de sus amigos como Capitán, Andrés de Monjaraz, un hombre "tullido de bubas ... que no era para hacer cosa que buena fuese" (Díaz del Castillo 1632: 491). Debido a las desacertadas decisiones del factor, los indígenas "estaban muy victoriosos; y ... México estaba cada día para alzarse” (Díaz del Castillo 1632: 491). La corrupción, la enfermedad y la debilidad en el campo de batalla suponen cualidades de deshonor que feminizan al factor y a sus aliados, en contraste con la dignidad, la salud y la fortaleza guerrera, que virilizan a Cortés y a sus hombres. No debemos olvidar que Díaz del Castillo es una masculinidad subordinada a Cortés, una filiación similar a la de Juana, motivo por el cual, en esta historia de buenos y malos, apoya a su propio bando.

Connell acuña el concepto de "masculinidades hegemónicas" (Connell y Messerschmidt 2005: 831) en su publicación de 1987 titulada Gender and Power. Los estudios sobre masculinidades hegemónicas analizan la creación de roles, y la articulación de redes y prácticas que marcan la posición dominante del hombre frente a la posición subordinada de la mujer además de otras identidades de género, que se perciben como "femeninas" en una sociedad dada. Definimos las masculinidades hegemónicas como construcciones sociales que representan el modelo de un hombre con poder en un contexto geográfico y temporal específico. Como señalan Connell y Messerschmidt en su reciente revisión de estos términos:

Hegemonic masculinity was distinguished from other masculinities, especially subordinated masculinities. Hegemonic masculinity was not assumed to be normal in the statistical sense; only a minority of men might enact it. But it was certainly normative. It embodied the currently most honored way of being a man, it required all other men to position themselves in relation to it, and it ideologically legitimated the global subordination of women to men. (2005: 832) 
El modelo de varón no se alza con la jefatura de una manera "natural" sino que debe ser reconocido como tal por otras masculinidades que podríamos denominar como subalternas. Es decir, aquellos varones que no alcanzan el modelo del "hombre de verdad" en un determinado tiempo y lugar son los mismos que deciden sostener este sistema jerárquico, quizás sin ser conscientes del poder que ellos mismos ejercen dentro de este sistema sexo-genérico. En la dinámica de la narrativa que nos ocupa Salazar y sus partidarios por un lado, y Cortés y los viejos conquistadores por otro, se conforman en distintos momentos como masculinidades hegemónicas en pugna por el poder. En esta línea de pensamiento, también las mujeres se articulan en torno a la masculinidad, bien a través de su relación o filiación con un hombre o bien por medio de un performance masculino. En cualquier caso, ellas, desde su posición de inferioridad, también son las que deciden reconocer a ese grupo limitado de hombres que poseen un lugar de poder a los que desean afiliarse, para lograr a través de su dependencia como novias, esposas, madres o amantes una posición de relativa hegemonía. Este es precisamente el papel que habitará Juana de Mansilla dentro de la narrativa que nos ocupa.

Como estrategia para legitimar el cambio de poder, Salazar celebra ceremonias públicas en las que la afiliación entre Juana y los viejos conquistadores resulta evidente. Curiosamente, tras visitar Xicalango, donde habían fallecido varios españoles, Ordaz asume que Cortés y sus hombres también habían muerto allí, y así se lo comunica por carta al factor. Salazar rápidamente acepta el supuesto fallecimiento como un hecho cierto, probablemente más por interés personal que por pruebas reales, ya que sin enemigos en el frente nadie puede arrebatarle su liderazgo. Salazar "se puso de luto, hizo hacer un túmulo y un monumento en la iglesia mayor de México en que hizo las honras por Cortés; y luego se hizo pregonar con trompetas y atabales por gobernador y Capitán general de la Nueva España" (Díaz del Castillo 1632: 491). Para que no quedara duda de la muerte de Cortés y sus hombres, y por tanto de la legitimidad de su cargo, "mandó que todas las mujeres que se habían muerto sus maridos en compañía de Cortés que hiciesen bien por sus ánimas y se casasen" (Díaz del Castillo 1632: 491). Nuestro acercamiento a la representación del género y el poder en la historia expone que en realidad las relaciones se establecen entre varones: Salazar y sus aliados, por una parte, y los viejos conquistadores, por otra. Juana de Mansilla es simplemente un objeto de intercambio utilizado por estas masculinidades hegemónicas según conviene a la versión de la historia que pretenden fijar. Va resultando cada vez más evidente que el papel que juega la dama en la narrativa de Díaz del Castillo relaciona el poder político con la construcción social del género.

\section{Acercamiento teórico: feminidades enfatizadas y masculinidades hegemónicas}

La sociedad en que se inserta Juana de Mansilla se fundamenta en una construcción binaria del género en que la mujer es percibida como un individuo dependiente, débil y sumiso cuya existencia gira, como un satélite, alrededor de la vida de los hombres. Los roles de género se entienden como modelos que condensan el ideal de masculinidad o feminidad en una comunidad a través de su performance. Como indica Butler (2006 [1990]) en Gender Trouble el género es una construcción social en la que el individuo se ve obligado a encajar en parámetros de iden- 
tidad a través de sus actos. Es decir, un hombre o una mujer sólo son considerados como tales, tanto por la colectividad como por ellos mismos, cuando su performance público se aviene a los modelos establecidos para su género (Butler 2006 [1990]: 45). Dentro del contexto patriarcal y católico del siglo XVI, como indica Fray Luis de León en La perfecta casada (1943), la mujer debe ser sumisa, modesta y permanecer apartada de las calles, para probar su fidelidad al esposo. Sin embargo, aunque la identidad de género está construida socialmente, no está totalmente construida lo que permite que los individuos puedan subvertir ciertas dinámicas, a través de esta teatralidad. En este sentido, Díaz del Castillo parece ofrecernos la oportunidad de redefinir los roles de género al presentarnos a una mujer que al mismo tiempo se resiste al poder masculino y se integra dentro de un sistema hegemónico-patriarcal. El personaje femenino, al formar parte de esta producción cultural y contexto geográfico, se inserta en un juego de equilibrios y desequilibrios, resistencias e incorporaciones, que le permiten desarrollarse a través de las dinámicas del género y el poder.

Dentro de la narrativa que propone Díaz del Castillo, Juana de Mansilla, se convierte en un cuerpo vulnerable al desafiar la masculinidad hegemónica ejemplificada por el factor Salazar. Judith Butler (2006) en Vida precaria llama la atención sobre la constitución de identidades frágiles en la sociedad. De acuerdo a Butler (2006), resultan precarios aquellos cuerpos que no ven cubiertas ciertas necesidades económicas, políticas y sociales que les permiten subsistir. La joven, como esposa de Valiente, resulta un cuerpo precario puesto que tras el supuesto fallecimiento de su pareja sabe que tendrá que casarse como ordena el espíritu vengativo de los enemigos de su esposo. Juana resulta entonces doblemente precarizada, primero por su condición femenina y segundo por la adscripción a una figura masculina de poder, Alonso Valiente, que como Cortés, acaba de ser destronado. Bourdieu considera que la dominación masculina basada en la jerarquía de los atributos varoniles sobre los femeniles supone "la violencia amortiguada, insensible, e invisible para sus propias víctimas, que se ejerce a través de los caminos puramente simbólicos de la comunicación y del conocimiento, o más exactamente, del desconocimiento, del reconocimiento, o en último término, del sentimiento" (2000: 12). Si el género se construye de manera performativaa través de las relaciones de poder así como de las restricciones normativas heterosexuales, sólo resistiéndose al tomar un performance masculino puede la protagonista mantener su fidelidad al marido. Es decir, para seguir perteneciendo al ideal católico de la buena esposa, la protagonista debe levantar su voz y negarse a las órdenes del factor Salazar con un accionar subversivo, propio del varón, pero cuyo performance queda justificado en la lógica de la historia.

Connell y Messerschmidt (2005) reflexionan sobre la formulación del concepto de "masculinidad hegemónica" en relación con la denominada "feminidad enfatizada" (848). En su revisión de estos términos consideran que las mujeres - como novias o parejas sexuales en el campo sentimental — participan de los procesos que construyen a las masculinidades. Por tanto, debe darse más atención a las prácticas de las mujeres así como a las dinámicas históricas entre lo femenino y lo masculino (2005: 848). Juana de Mansilla, de acuerdo a los patrones históricos y temporales de quienes crean su narrativa, accede a una posición de privilegio a través de la filiación con los hombres: en este caso su esposo Alonso Valiente y su líder, Hernán Cortés. Por tanto, las decisiones de la protagonista, más que mostrar su autonomía o disidencia, legitiman los patrones machistas con los que opera esta sociedad, ya que ella misma se percibe como 
una extensión del cuerpo de su esposo. Esta fidelidad absoluta, que pone en peligro su propia supervivencia, se extiende más allá de la figura de Alonso Valiente, ya que a través de su esposo reclama la legítima autoridad de los primeros conquistadores de la Nueva España en un discurso de poder sexo/genérico. Es decir, nunca observamos a una mujer independiente puesto que Juana, como esposa abnegada, acepta de forma estoica la misma honra o deshonra, honor o deshonor, fortuna o infortunio, que sufre su esposo. En este sentido podemos decir que Díaz del Castillo nos presenta a Juana a través de una mirada masculina, la del propio autor, pero también la de la sociedad en la que se inscribe su historia.

\section{Juana de Mansilla: la apropiación patriarcal del cuerpo y la voz de la mujer}

A través de la voz de Juana, Díaz del Castillo legitima la autoridad de los primeros conquistadores de la Nueva España en detrimento de una nueva clase de burócratas, que no dominan los dispositivos de la conquista. Juana de Mansilla al proclamar la existencia de su esposo apoya el honor de los viejos conquistadores, aquellos que ganaron la tierra por medio de la lucha armada, frente al gobierno de una nueva clase política, corrupta e incompetente (a la que representan el factor Salazar y sus partidarios). De acuerdo al autor, Juana:

dijo que su marido y Cortés y todos nosotros eramos vivos, y que no éramos los conquistadores viejos de tan poco ánimo como los que están el peñol de Coatlán con el veedor Chirinos, y que los indios les daban guerra y no ellos a los indios, y que tenía la esperanza en Dios que presto vería a su marido Alonso Valiente y a Cortés y a todos los demás conquistadores de vuelta para México, y que no se quería casar. (Díaz del Castillo 1632: 492).

Juana no se limita a expresar que su esposo está vivo y por tanto preparado para regresar y retomar su posición de poder, una afirmación que en este contexto suena a amenaza, sino que critica abiertamente a las nuevas masculinidades, representantes de la burocracia, que ejemplifica el factor. Díaz del Castillo, por boca de Juana, critica a una nueva clase política que no ha ganado la tierra por medio de la guerra, como los viejos conquistadores, sino que la ha tomado por medio de argucias políticas y corruptelas. También señala la incapacidad del nuevo gobierno de mantener la tierra ganada libre de rebeliones indígenas, aspecto evidente al mencionar el fracaso del veedor Chirinos en Coatlán. En su discurso, Juana coloca a Cortés y a sus hombres del lado de Dios y de la justicia, y por tanto sugiere que el gobierno de Salazar está dirigido por la ilegalidad y los influjos del maligno.

La dialéctica de Juana propone una feminización de los dirigentes corruptos en el presente del relato, en contraste con una masculinización que glorifica a los viejos conquistadores. Díaz del Castillo usa la voz de Juana para desautorizar a las nuevas masculinidades a través de un discurso de género, puesto que no dominan los dispositivos del poder patriarcal en la primera fase de la conquista; es decir, las armas, las estrategias militares e incluso el arrojo del que hacen gala los hombres de Cortés. En este sentido, ante un periodo de crisis en que las masculinidades que habitan en la ciudad no se atreven a enfrentarse al factor, Juana asume la posición de los 
hombres con los que mantiene un lazo de filiación. La mujer, concebida en la sociedad virreinal como un cuerpo sin voz, sólo se permite hablar para transmitir el mensaje de los viejos conquistadores. Va resultando evidente que el performance de Juana tiene poco o nada que ver con lo femenino, ya que ante la ausencia de Valiente, la presencia de la mujer no resulta propositiva sino quese limita a reproducir "la voz de su amo". Podríamos decir que la joven esposa se masculiniza al expresarse con honor y fortaleza, cualidades varoniles ajenas a su género en el contexto virreinal.

La decisión del factor, que obliga a las mujeres a contraer matrimonio, supone una politización de la sexualidad que se apropia de los cuerpos de las hembras para garantizar la reproducción. Dentro del sistema heteropatriarcal de la sociedad virreinal los cuerpos de las féminas son mercancías que se intercambian entre los varones a través de pactos familiares y económicos. Los organismos valorados por los varones son los de las mujeres en edad reproductiva ya que el nacimiento de niños es esencial para preservar y continuar la ideología de las masculinidades que se encuentran en el poder. Como afirma Bethell "el matrimonio aseguró la colonización y la estabilidad que la corona española había tratado de establecer y mantener en el nuevo orden colonial" (111-112).

El autonombrado gobernador y capitán general, dentro de una narrativa que une conquista y romance, no sólo toma la tierra sino que se apropia de los cuerpos de las mujeres que la habitan. Ruiz-Tresgallo propone que el discurso de la ganancia o la pérdida de un territorio es similar al alegato sentimental — porque la tierra, como si fuera una mujer deseada, puede ser asediada, conquistada o perdida a manos de un rival (2010:296) —. De acuerdo a la propuesta de Ruiz-Tresgallo, el mandato de Salazar supone un acto de desposesión, desde una perspectiva masculina, tanto del territorio geográfico como de los territorios femeninos de sus propietarios legítimos: los viejos conquistadores. Salazar no puede enfrentarse a Cortés y sus hombres en batalla, ya que no domina el discurso varonil de las armas. Sin embargo, como medida compensatoria, sí domina otro espacio de poder patriarcal, el alegato legal de las letras que le permite disciplinar el cuerpo femenino.

La relación entre política y hechicería que nos ocupa en este ensayo no es nueva. En concreto Lima (2005) menciona el caso del padre Urbain Grandier que desde el púlpito denunciaba los excesos del gobierno y se oponía a la centralización del poder en París a coste de la autonomía local. Richelieu, incapaz de condenar a Grandier en el terreno político, lo acusó de mantener un pacto con el diablo. De hecho, el nombre de Grandier se asocia al convento de las ursulinas de Loudun en la Francia de Luis XIII, donde se le acusó de poseer carnalmente a varias monjas a través del poder del demonio (160). Richelieu, por medio de una acusación falsa: la práctica de las artes ocultas, logra eliminar a quién se niega a obedecer sus leyes. De modo análogo, en el caso de la esposa de Valiente, la acusación de hechicería pretende desterrar toda resistencia al mandato del factor.

En realidad, Juana no es condenada por practicar rituales mágicos, sino porque en vez de ser un cuerpo dócil y obediente, levanta su voz disidente ante un hombre que se encuentra en una posición de poder. La dama habla con palabras que muestran su insubordinación ante Salazar y que suponen una transgresión del papel sumiso de la mujer en el virreinato. Barbara Weissberger afirma: "The rule of a woman inevitable created anxiety, confusion and resistance in a patriarchal society grounded in the theological subordination of women to men" (2002: 208). Salazar, para 
restablecer su liderazgo ante la rebeldía de Juana de Mansilla, la acusa de hechicería y la castiga de modo público y ejemplar. Díaz del Castillo expresa: “y porque dijo estas palabras la mandó azotar el factor por las calles de México por hechicera” (1632: 492). Federici (2010 [2004]) sostiene que "hacia el siglo XVI el ataque de la magia estaba ya en su apogeo y las mujeres eran sus objetivos más probables" (239). Recordemos que ya en el siglo XV el Malleus Maleficarum o Martillo de las brujas (1486), manual atribuido a los inquisidores dominicos Heinrich Kramer y Jacob Sprenger, perseguía fundamentalmente a las hembras al considerarlas más débiles a los influjos del demonio. A lo largo de la historia, la acusación por la práctica de la nigromancia ha sido el castigo adjudicado a la mujer por resistirse a los dictados del patriarcado. Además la voz de las féminas siempre ha sido acallada, de hecho a las "regañonas" se las hacía desfilar públicamente con una "brida" puesta, un artefacto de hierro que se usaba para inhabilitar a las hembras de lengua afilada (Federici 2010 [2004]: 153). Con su sentencia, el factor quiere demostrar que la creencia de Juana en la vida de su cónyuge y de los hombres de Cortés es sólo una fantasía del demonio puesto que tanto la imputación como el castigo desautorizan el logos de la esposa de Alonso Valiente.

Sugerimos que el correctivo proporcionado por el factor Salazar al cuerpo de Juana de Mansilla supone una humillación pública que pretende en realidad la deshonra de los viejos conquistadores; las figuras masculinas a las que la dama está vinculada. Johnson y Lipsett-Rivera consideran que el tratamiento brutal de Salazar con Juana "was intended as a punishment and a public humiliation: he sought to injure both her body and her honor" (1998: 1). Aunque estamos de acuerdo con esta valoración discrepamos en el alcance de este acto ya que la deshonra no se limita a su ser, sino que, a través del organismo de Juana el nuevo gobernador pretende humillar públicamente a su esposo Valiente y a los hombres de Cortés. Con la profanación y el sacrificio del cuerpo femenino, abierto y expuesto al escarnio público, el factor despliega la extensión de su poder, pero también su crueldad e injusticia ante una de las mujeres principales del virreinato. Por llevar a cabo sus deseos, el nuevo gobernador está dispuesto a transgredir cualquier límite, incluso ofender gravemente el honor de los viejos conquistadores de México al execrar el cuerpo de una de sus esposas. De hecho, ese parece ser su objetivo ya que las mujeres, al considerarse objetos adscritos a sus poseedores, pueden ser utilizados por otros hombres para sobajar a una masculinidad adversaria.

Díaz del Castillo nos presenta el performance de Salazar como un acto de cobardía, ya que ataca a una mujer indefensa en vez de a las masculinidades a las que realmente quiere destruir y sustituir. Debido a la función de la violencia en el aparato represor del estado, con este acto el nuevo capitán general pretende la dominación física y moral del otro. El trazo por excelencia de la soberanía es la exhibición del poder de la tortura y la muerte entre los destinados a permanecer vivos. En este sentido el cuerpo de Juana supone una advertencia del castigo que sufrirán tanto aquellos que guarden fidelidad a los viejos conquistadores como las masculinidades que pretendan destronar al recién autonombrado gobernador.

La violencia aplicada sobre el cuerpo de la joven tiene la marca de la masculinidad ya que los hombres son los destinatarios del mensaje inscrito en este territorio. Segato (2013) considera que "por su calidad de violencia expresiva más que instrumental —violencia cuya finalidad es la expresión del control absoluto de una voluntad sobre otra- la agresión más próxima a la violación es la tortura, física y moral" (21). La marca del control territorial puede ser inscrita en el cuerpo de las mujeres como parte o extensión de un dominio afirmado como propio. El 
público son los hombres que presencian estos actos desde la horizontalidad de lo masculino, es decir, las marcas dejadas en los cuerpos de las mujeres indican que quien las ha agredido es un varón. La vara, el látigo o las cuerdas con las que probablemente se ejercieron los azotes en el cuerpo de Juana poseen un carácter fálico que señala que quienes imparten el castigo son los hombres. La acusación de hechicería permite precisamente la justificación del ejercicio del tormento sobre el cuerpo de la mujer, una violencia realizada por los varones ya que como afirma Weisz: "los verdugos crean un sentido de identidad criminal compartida entre los hombres, la unidad que caracteriza al grupo es un odio hacia la mujer y a las brujas como su pretexto" (2015: 58).

Foucault (2002 [1971]) al reflexionar sobre las normas de la tortura pública corrobora que:

esta producción está sometida a reglas. El suplicio pone en correlación el tipo de perjuicio corporal, la calidad, la intensidad, la duración de los sufrimientos con la gravedad del delito, la persona del delincuente y la categoría de sus víctimas. El suplicio forma, además, parte de un ritual. Es un elemento en la liturgia punitiva, y que responde a dos exigencias. Con relación a la víctima, debe ser señalado: está destinado, ya sea por la cicatriz que deja en el cuerpo, ya por la resonancia que lo acompaña, a volver infame a aquel que es su víctima; el propio suplicio, si bien tiene por función la de "purgar" el delito, no reconcilia; traza en torno o, mejor dicho, sobre el cuerpo mismo del condenado unos signos que no deben borrarse; la memoria de los hombres, en todo caso, conservará el recuerdo de la exposición, de la picota, de la tortura y del sufrimiento debidamente comprobados. Y por parte de la justicia que lo impone, el suplicio debe ser resonante, y debe ser comprobado por todos, en cierto modo como su triunfo. (2002 [1971]): 33-34)

El suplicio de Juana deja rastros de deshonor no sólo en su cuerpo sino en la memoria colectiva, puesto que es un acto público que ejemplifica el triunfo de las nuevas masculinidades sobre los viejos conquistadores al marcar el cuerpo de una mujer. Si como afirma Foucault (2002 [1971]), la tortura pública tiene sus propias normas, cuando una masculinidad hegemónica sobaja a Juana sólo otra masculinidad con poder puede devolverle el honor. En esta sociedad, basada en la construcción binaria del género, las mujeres no se configuran como entes autónomos sino como seres dependientes sobre los que los hombres depositan la honra o la deshonra.

Para dar un nuevo significado a las marcas del cuerpo de Juana y devolverle su dignidad un nuevo evento debe tener lugar: la restauración pública del honor de la esposa de Alonso Valiente. Para que este performance sea efectivo debe venir previamente acompañado de la restitución oficial de las masculinidades con las que se afilia nuestra protagonista ya que sin el aval de la autoridad su acción no tendría valor. Si bien en el pasado el factor hizo monumentos funerarios en un alarde público para demostrar la muerte de Cortés, ahora Hernán cabalga por las calles con sus partidarios acompañado por los vítores que manifiestan su existencia y legitimación real: "Viva el rey nuestro señor y Hernando Cortés en su real nombre, que es vivo y viene ahora a esta ciudad" (Díaz del Castillo 1632: 498). Tras encarcelar al factor y al veedor, el primer acto que realiza el tesorero es:

mandar honrar a Juana de Mansilla que había mandado azotar el factor por hechicera, mujer de Alonso Valiente, y fue de esta manera. Que mandó cabalgar a caballo a todos los caballeros de 
México, y el mismo tesorero la llevó a las ancas de su caballo por las calles de México; y decían que como matrona romana hizo lo que hizo, y la volvió en su honra de la afrenta que el factor le había hecho, y con mucho regocijo la llamaron desde allí adelante la señora Doña Juana de Mansilla; y dijeron que era digna de mucho loor, pues no pudo hacer el factor que se casase, ni dijese menos que lo primero había dicho que su marido y Cortés y todos éramos vivos." (Díaz del Castillo 1632: 499).

De acuerdo al discurso patriarcal, Doña Juana ha salido ganando con su desgracia, puesto que ha aumentado su honra al ser "endonada" y alabada como "matrona romana" por las calles de México. En el siglo XVI el grado de doña era el nombre que recibía una mujer perteneciente a la nobleza, estatus social tan elevado que sus miembros eran prácticamente intocables (Johnson y Lipsett-Rivera 1998: 1). Prueba de la excepcionalidad de este nombramiento entre las mujeres del virreinato es que “iNi la riquísima Catalina Vélez Rascón había sido endonada!” (Cruz 2009: 120). Juana de Mansilla, no sólo es restaurada públicamente en su honor, sino que su ascenso sugiere el empoderamiento de un conquistador, puesto que desfila a lomos de un caballo, dispositivo del poder masculino que identifica a los militares a los que defendió. En la dinámica sexo-genérica de la sociedad virreinal la mujer sólo puede acceder al poder a través de los hombres: o por una relación filial o masculinizándose. Sin embargo, como hemos sostenido a lo largo de este ensayo la supuesta masculinización de Juana de Mansilla es meramente circunstancial ya que adopta el papel de su esposo en un momento de crisis para después incorporarse al discurso triunfante de los vencedores en un alegato maternal y sumiso propio del patriarcado. Es decir, en todo momento la narración dibuja a Juana desde una perspectiva masculina, la de Díaz del Castillo, pero también la de los hombres que protagonizan el relato.

La terminología que utiliza Díaz del Castillo, invierte la interpretación del papel de Juana, ya que como por arte de magia pasa de ser hechicera, el estereotipo femenino más denostado en la sociedad patriarcal, a "matrona romana", el modelo superior de virtud y patriotismo en esta civilización. Las matronas romanas además de realizar las tareas adjudicadas tradicionalmente a la mujer, como encargarse de la casa y gobernar a los sirvientes, dirigían los negocios o asuntos militares del esposo en su ausencia. Como prueba de su fidelidad más allá de la muerte, en general, no se casaban al enviudar, manteniendo vivo el legado de su cónyuge. El performance de Juana se aviene a este modelo de máxima virtud femenina, ya que ante la ausencia de su esposo ella misma toma su lugar, negando su autonomía y convirtiéndose de esta manera en una extensión más del cuerpo de su pareja. Las alabanzas a nuestra protagonista no resultan baladís, ya que tanto su ascenso al título de Doña como su reconocimiento como "matrona romana" le dan un grado de nobleza y respeto que no se limita a su ser sino que trasciende a los viejos conquistadores con quienes tiene una relación de filiación. Sin duda, la elevación pública del cuerpo de Juana autoriza tanto el nuevo gobierno como el discurso imperial de los vencedores.

El ejemplo de la esposa de Alonso Valiente nos recuerda en especial el de Juana de Arco, ya que también esta dama, fue acusada de brujería en un momento de la historia para posteriormente ser santificada por el patriarcado. La doncella de Orleans afirmó tener la misión divina de dirigir el ejército francés, coronar como rey al delfín en Reims y expulsar a los ingleses del país. Gracias al apoyo del entonces príncipe Carlos, Juana de Arco llegó a dirigir un ejército de 5.000 hombres, pero el rey, una vez logrados sus objetivos, la abandonó puesto que fue entregada a los 
ingleses y juzgada por un tribunal eclesiástico acusada de brujería y herejía. Sorprende comprobar como la masculinización de Juana de Arco, al vestirse con ropas de varón, fue un elemento que causó su condena en la hoguera el 30 de mayo de 1431 (Evans 2017: 18). Recordemos que Juana de Mansilla también es condenada al actuar como un hombre, en concreto al impugnar los mandatos de Salazar. Curiosamente, en 1456, Juana de Arco fue rehabilitada por el papa Calixto III, a instancias de Carlos VII. Resulta evidente el uso político de Juana de Arco por parte de la masculinidad hegemónica ya que el mismo rey que la había utilizado para coronarse, fue quien permitió su ejecución y después solicitó su rehabilitación. De modo similar, Juana de Mansilla resulta condenada o rehabilitada según los intereses políticos de las masculinidades que ostentan la jefatura. En época más reciente la doncella de Orleans fue reverenciada como mártir, beatificada, canonizada y convertida en patrona de Francia. Al igual que en el caso de Juana de Mansilla - finalmente venerada, endonada y transformada en una virtuosa matrona de México- el patriarcado puede extraer un beneficio político de los cuerpos de las mujeres torturadas.

\section{Reflexiones finales}

El caso de Juana de Mansilla, incluido por Díaz del Castillo en Historia verdadera de la conquista de la Nueva España, descubre las dinámicas que se desarrollan entre el poder político, la construcción binaria del género y la imputación de hechicería. El autor construye a Juana de Mansilla como un tropo que el patriarcado demoniza o ensalza de acuerdo a sus intereses políticos. En el texto, siempre observamos a nuestra protagonista desde una perspectiva masculina, la que conviene al autor y la de los varones poderosos con quien se relaciona la dama. Consideramos que, aunque Juana aparentemente invierte los papeles adjudicados a cada género — puesto que toma el rol de los hombres, al enfrentarse al factor y apoderarse del logos masculino- en realidad ofrece una imagen de falso empoderamiento femenino. A primera vista podría parecer que Juana es una mujer autónoma y disidente, pero, como hemos expuesto en este ensayo, Díaz del Castillo simplemente la dibuja como un ser anulado; una mera extensión del cuerpo y la voz de su esposo. Proponemos que el correctivo inscrito por Salazar en el cuerpo de la joven supone un tipo de humillación pública que pretende la deshonra de Cortés y sus hombres; las figuras masculinas a las que la dama está afiliada.

El método de incorporación de la "hechicera" Juana al discurso patriarcal de los vencedores, expone su inclusión dentro del orden recién restaurado con un alegato familiar adaptado a los valores políticos y religiosos de la madre patria. Juana de Mansilla, se suma a una lista de mujeres polémicas que son restauradas en la narrativa política imperial como santas, vírgenes y/o madres. Sin embargo, la mujer y su performance no varían; es el discurso patriarcal que se conforma a su alrededor, el que demoniza o santifica a estas mujeres para extraer una ganancia política de las múltiples violencias ejercidas sobre ellas. 


\section{Referencias bibliográficas}

Bethell, L. (1990). Historia de América Latina. Barcelona: Editorial Crítica.

Bourdieu, P. (2000). La dominación masculina. Barcelona, España: Anagrama.

Butler, J. (2006 [1990]). Gender Trouble. Nueva York: Routledge. . (2006). Vida Precaria. Buenos Aires: Paidós.

Connell, R. W.; \& Messerschmidt J. W. (2005). Hegemonic Masculinity: Rethinking the Concept. Gender \& Society, 19, 6, 829-859.

Díaz del Castillo, B. (1986 [1632]). Historia verdadera de la conquista de la Nueva España. México: Porrúa.

Donoso Anes, A. (2008). Organización y funcionamiento administrativo y contable de la Real Hacienda de Indias en Tiempo de los Austrias a la luz de la legislación aplicable. De Computis: Revista Española de Historia de la Contabilidad, 5 9, 48-96.

Evans, A. (2017 [1978]). Brujería y contracultura gay. México: Colectivo Pensaré.

Federici, S. (2010 [2004]). Calibán y la bruja. Mujeres, cuerpo y acumulación originaria. V. Hendel, \& L. S. Touza (Trads). Madrid: Traficantes de sueños.

Foucault, M. (2002 [1971]). Vigilar y castigar: nacimiento de la prisión. Buenos Aires: Siglo XXI editores.

Johnson, L. L.; \& Lipsett-Rivera, S. (1998). Introduction. In The Faces of Honor: Sex, Shame, and Violence in Colonial Latin America (pp. 1-17). Albuquerque: University of Mexico Press.

Kramer, H.; \& Sprenger J. (1971). The Malleus Maleficarum of Heinrich Kramer and James Sprenger. M. Summers (Trad.). New York: Dover Publications.

León, F. L. de. (1943). La perfecta casada. Buenos Aires: Espasa-Calpe Argentina.

Lima, R. (2005). A Matter of Habit: The Politics of Demonic Hysteria in John Whiting's The Devils. In Stages of Evil: Occultism in Western Theater and Drama (pp. 159-176). Lexington: University of Kentucky.

López de Gómara, F. (2007 [1552]). Historia de la conquista de México. Venezuela: Ayacucho.

Ruiz-Tresgallo, S. (2010). Nation and Woman: from Conquered to Conqueror in Los Estados-Unidos (notas y episodios de viaje) by Alberto Lombardo. Romance Notes, 50, 3, 295-306.

Segato, R. (2013 [2006]). La escritura en el cuerpo de las mujeres asesinadas en Ciudad Juárez. Territorio, soberanía y crímenes de segundo estado. Buenos Aires: Tinta Limón.

Weissberger, B. F. (2002). Deceitful Sects: The Debate about Women in the Age of Isabel the Catholic. In T. S. Fenster, \& C. A. Lees (Eds.), Gender in Debate From the Early Middle Ages to the Renaissance (pp. 207-235). New York: Palgrave Macmillan.

Weisz, G. (2015). Estigma de bruja. In M. Fe (Coord.), Mujeres en la hoguera: representaciones culturales y literarias de la figura de la bruja (pp. 53-62). México: UNAM. 